\title{
Five Years of Pulsed Current Testing for HVDC Switchgear
}

\section{Conference Paper}

Author(s):

Ritter, Andreas (D); Bort, Lorenz (iD; Franck, Christian (1)

Publication date:

2016

Permanent link:

https://doi.org/10.3929/ethz-b-000123382

Rights / license:

In Copyright - Non-Commercial Use Permitted

Originally published in:

https://doi.org/10.1109/ICHVE.2016.7800658 


\title{
Five Years of Pulsed Current Testing for HVDC Switchgear
}

\author{
A. Ritter, L. S. J. Bort, C. M. Franck \\ High Voltage Laboratory (HVL) \\ ETH Zurich \\ Zurich, Switzerland \\ rittera@ethz.ch
}

\begin{abstract}
Since passing its commissioning tests in early August 2011, the flexible pulsed dc current source (FPDCS) at ETH's high voltage laboratory has enabled research in different areas of HVDC switchgear as well as its applications with an unprecedented variability and flexibility, establishing many new research opportunities. Over the course of five years of continuous use, a significant number of incremental upgrades were made to hardware, software and to the application practices. Different fields of application were identified and a number of future upgrades were determined, when testing circuit-breaker components, disconnectors and even power semiconductors using FPDCS. In this publication, we strive to share our experiences and recommendations for construction, operation and enhancement of similar current sources for research, development and commercial operation.
\end{abstract}

Keywords-pulsed current, current source, testing, HVDC switchgear

\section{INTRODUCTION}

The ever increasing, world-wide deployment of HVDC equipment of different types for widely varying applications such as back to back converters, point to point connections and even multiterminal networks (cf. [1]) has necessitated the availability of a variety of test setups capable of performing tasks from small-scale research to high voltage type tests. While voltage sources for DC insulation tests have been commonly available for decades, high current DC sources remained sparse mostly due to a lack of applications. However, the recent increase in research and development activities surrounding HVDC circuit breakers (CB) has renewed interest in such current sources. Testing full-scale HVDC $\mathrm{CB}$ is generally estimated to require currents of $10 \mathrm{kA}$ or more rising within a few milliseconds in combination with sufficient recovery voltage in order to model fault behavior of an HVDC grid, as explained by Smeets in [2]. However, in research and development tests of $\mathrm{CB}$ components, significantly higher current gradients have to produced, particularly when evaluating resonance performance and arc characteristics (cf. [3], [4]). For this very reason, an initial plan for building a current source capable of delivering current pulses at a maximum amplitude of $20 \mathrm{kA}$ at gradients of up to $200 \mathrm{kA} / \mathrm{ms}$ was presented in 2010 by Walter (cf. [5]). Within one year, the flexible pulsed DC current source (FPDCS) was developed and commissioned at ETH Zurich's high voltage laboratory.

978-1-5090-0496-6/16/\$31.00 ๑2016 IEEE
FPDCS' final current rating was set to $3 \mathrm{kA}$ at gradients of up to $50 \mathrm{kA} / \mathrm{ms}$ using power electronics and control systems optimized for cost, delivery time and energy storage. In the time since its commissioning, FPDCS has been in continuous use while receiving intermittent upgrades to improve performance, safety and measurement accuracy. Many of the results gathered from tests using FPDCS on different loads have been published (cf. [6]-[8]) while more are certainly to follow (cf. [9]).

\section{OPERATING PRINCIPLE \& APPLICATIONS}

The main operating principle of FPDCS is that of three identical buck converter modules $\left(\mathrm{M}_{1} \ldots \mathrm{M}_{3}\right)$ connected in parallel to provide a controllable current $i_{\mathrm{L}}$ to a variable load as shown in the equivalent circuit diagram of Figure 1. The peak output currents $i_{1}, i_{2}$ and $i_{3}$ are limited to $1 \mathrm{kA}$ each by the ratings of diodes $\left(D_{1} \ldots D_{3}\right)$ and IGBTs $\left(S_{1} \ldots S_{3}\right)$. The entire energy supplied to the load during one test is stored in three parallel connected capacitors $\left(\mathrm{C}_{1} \ldots \mathrm{C}_{3}\right)$ with a capacitance of $2 \mathrm{mF}$ each and a maximum charging voltage of $3 \mathrm{kV}$. This enables tests with peak powers of up to $9 \mathrm{MW}$ with total durations up to a few hundred milliseconds. The capacitors are not recharged while supplying a load, which permits the complete electrical isolation of FPDCS from any equipment other than the load during tests. The output inductances $\left(\mathrm{L}_{1} \ldots \mathrm{L}_{3}\right)$ can be individually varied in 26 steps between $6 \mu \mathrm{H}$

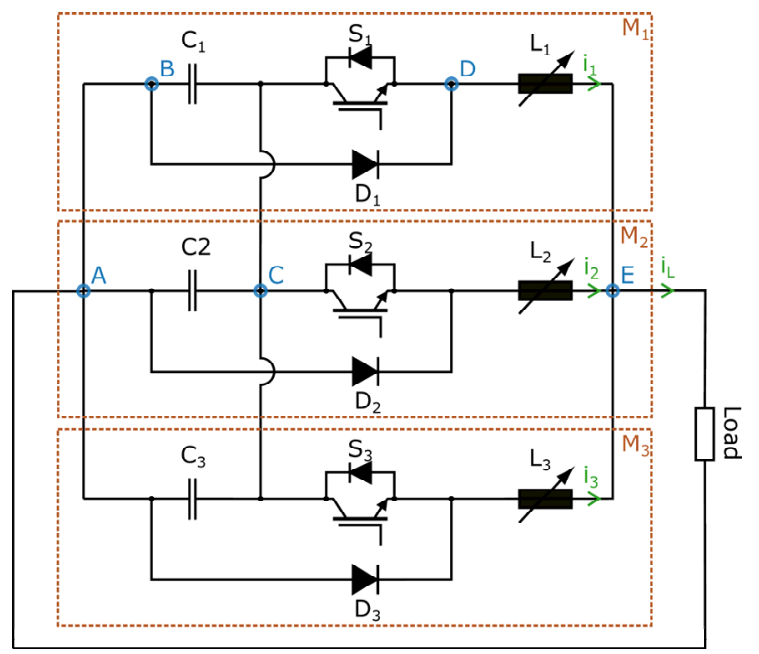

Fig. 1. Idealized equivalent circuit diagram of power part of FPDCS. 
and $4.5 \mathrm{mH}$. The control of $\mathrm{S}_{1} \ldots \mathrm{S}_{3}$ is split into a digital part, which determines when current starts flowing from the capacitor according to a set switching frequency. The signal for switching off the IGBTs is given by a high-speed analog part which compares the module currents $i_{1} \ldots i_{3}$ to their set values $i_{1}^{\text {set }} \ldots i_{3}^{\text {set }}$ continuously. From the circuit diagram in Figure 1, it is clear that the capacitor voltage (and therefore stored energy) decreases whenever the IGBT is conducting. The voltage across each module's inductance changes back and forth between the difference of capacitor voltage and load voltage whenever the IGBT is on and the negative load voltage whenever the IGBT is switched off. Therefore, jumps of up to $5000 \mathrm{~V}$ within microseconds across $\mathrm{L}_{1} \ldots \mathrm{L}_{3}$ can occur. The control hardware allows for a configurable phase shift between switching on modules, which permits the creation of complex output currents using moderate switching frequencies, as illustrated by the simulated ${ }^{1}$ currents in Figure 2. In addition, the set current of each module can be defined individually for any point in time prior to starting a test. This combination enables the operator to create intricate current waveforms such as the ones presented in [10]. Additionally, it opens up possibilities to rapidly adapt the output currents to different loads. Past and current applications include emulating HVDC grids for testing of a model CB (cf. [6]), providing different current harmonics for bus-transfer by disconnector, and destructive limit testing of power semiconductors.



Fig. 2. Simulation of testing a resistive load using different inductances (L1>L2 $\square$ L3) but identical set currents and phase shifts between switch-on times of $\mathrm{M}_{1} \ldots \mathrm{M}_{2}$.

\section{REAL WORLD CHALlENGES \& SOlutions}

Over the five years of using FPDCS, many different challenges had to be overcome which are not necessarily present in the idealized representation shown in Figures 1 and 2. Additionally, the area of operation was gradually extended through improvements on hardware and software as well as changes in usage practices.

\section{A. Limitted energy storage in capacitor before test}

When constructing FPDCS, the choice of three $2 \mathrm{mF}$ capacitors represented one of the main tradeoffs between performance, cost, safety and availability. In everyday operations, the capacitors limit three aspects of testing: First, the maximum energy which can be supplied to the load is $27 \mathrm{~kJ}$, setting limits mainly on duration and current magnitude. Secondly, the current gradient during increasing current is directly proportional to the voltage difference between the capacitors and the load, therefore decreasing with dissipated

${ }^{1}$ Simulation data rather than measurement results are shown to provide idealized explanations of the functioning principles. energy $^{2}$. Thirdly, if the load voltage rises above the capacitor voltage at any time during a test, the load current starts to decrease and eventually reaches zero. While only upgrading the capacitors can combat the first issue, the latter two are usually addressed by changing the module inductances, adjusting charging voltages and shortening test durations as shown in Figure 3, which illustrates points 2 and 3. To provide the load current $i_{a}(t)$, the IGBTs stayed on during the entire test duration of $20 \mathrm{~ms}$ but after $5 \mathrm{~ms}$ the load voltage reached a higher level than the capacitor voltage leading to a slow decay towards zero. By increasing the capacitor voltage, the desired current $i_{b}(t)$ could be achieved, albeit at a significantly higher initial gradient.

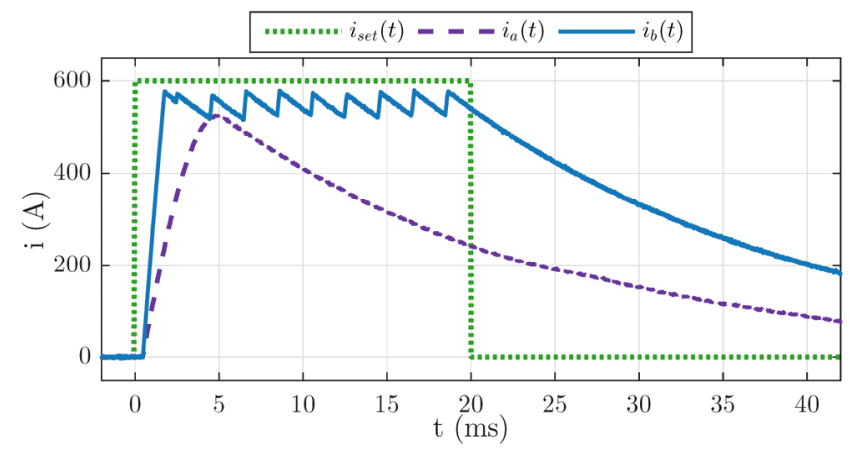

Fig. 3. Two tests using set current of $600 \mathrm{~A}$ for $20 \mathrm{~ms}$. The initial capacitor voltage was raised from $300 \mathrm{~V}\left(\mathrm{i}_{\mathrm{a}}(\mathrm{t})\right)$ to $700 \mathrm{~V}\left(\mathrm{i}_{\mathrm{b}}(\mathrm{t})\right)$, all other parameters including the load were left unchanged.

\section{B. Maximum temperature of power semiconductors}

Due to the short durations of each individual test, the switching and conduction losses generated by the power diodes and IGBTs heat almost exclusively their silicon dies. The maximum acceptable temperature rise of $100 \mathrm{~K}$, therefore, imposes a complex boundary on the number of switching operations as well as the set current levels and their durations. In order to maximize FPDCS' potential, its excellent predictability was made use of when implementing a worstcase thermal loss simulator which automatically predicts turn on, turn off and conduction losses in all semiconductors prior to any test. Before charging of the capacitor starts, the user is warned if the thermal losses would potentially damage a diode or an IGBT. Not only does this simulator protect the semiconductors from potentially damaging heating, it also allows the user to quickly evaluate the feasibility of certain test currents in advance.

\section{Power semiconductor particularities}

FPDCS' circuit shown in Figure 1 was chosen over more advanced DC-DC designs mainly due to its cost-effectiveness, the availability of components and the fact that it can be controlled by a fast and reliable control loop. As such, the chosen design relies on switching the IGBTs $\mathrm{S}_{1} \ldots \mathrm{S}_{3}$ off while current is flowing and on when voltage is applied (i.e. hard switching). Figure 4a) shows a typical switch-on operation of an IGBT whenever current was previously flowing through the freewheeling diode of the same module. The initial current rise is significant in its magnitude but well within the specifications of the IGBT modules in use in FPDCS because the inductance

2 This is fact is illustrated by the decreasing steepness of increasing current parts in Figure 2. 
of the commutation path (labels $\mathrm{B}$ and $\mathrm{D}$ in Figure 1) was minimized during construction. Other than the heating of the IGBT substrate - which is accounted for in the thermal simulator-this switching mode has no negative effect on FPDCS. Current waveforms b) and c) of Figure 4 show the two different recovery modes of the diodes $\mathrm{D}_{1} \ldots \mathrm{D}_{3}$. In both cases, a module with very low inductance is switched on for a short time $(10.5 \mu \mathrm{s}$ in $\mathrm{b}), 7.5 \mu \mathrm{s}$ in $\mathrm{c}))$ while a current of slow gradient is already provided by another module. When the current of the low inductance module reaches zero, the semiconductor diode needs a recovery charge of $560 \ldots 930 \mu \mathrm{C}$ in order to stop conducting. In case b) a soft recovery is observed, whereas in case c), snappy recovery leads to a rapid oscillation of the module current around zero, increasing its thermal losses ${ }^{3}$. While the high current gradients typical for snappy diode recovery does not pose a problem for FPDCS, it constitutes a potential failure mode: The total duration of reverse conduction of the diode in question is increased, which in turn increases the chance of an IGBT switching on in this state. Such an event has led to the only appreciable downtime FPDCS over its period of use.

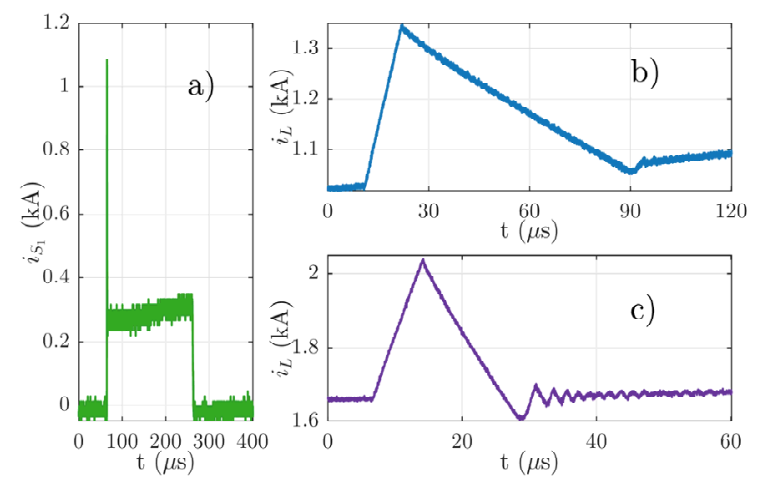

Fig. 4. Excerpts of currents measured during testing: a) Current through one IGBT of one module when delivering approximately $300 \mathrm{~A}$ for $150 \mu \mathrm{s}$, showing rapid initial current excursion to $1 \mathrm{kA}$ during diode recovery. b) total current $i_{L}$ during a current spike of $310 \mathrm{~A}$ ontop of $1 \mathrm{kA}$, exhibiting soft recovery at $\mathrm{t}=90 \mu \mathrm{s} ; \mathrm{c}$ ) total current $\mathrm{i}_{\mathrm{L}}$ during current spike of $380 \mathrm{~A}$ on $1.7 \mathrm{kA}$ followed by snappy diode recovery at $\mathrm{t}=26 \mu \mathrm{s}$.

\section{Inductances of wires and geometries}

The considerable current gradients of up to $50 \mathrm{kA} / \mathrm{ms}$ lead to extensive voltage drops along any inductance in series with the load ${ }^{4}$. Initially, FPDCS was located in a separate room, some distance away from the devices under test and connected through bus bars of $12 \mu \mathrm{H}$. Since FPDCS was grounded at the capacitors (point A in Figure 1), a worst case drop of $600 \mathrm{~V}$ along these bus bars meant that the low voltage side of the load reached $300 \mathrm{~V}$, making differential voltage measurements and potential free current measurements inevitable. During a major rebuild of FPDCS in 2015, the distances between source modules and loads was shortened by a factor of five, lowering the inductive voltage drops substantially. Additionally, the grounding scheme of the modules was revised in order to remove all ground connections during tests except for one which can be freely placed by the user. This not only enables the use of a shunt resistor for current measurement but also provides the ability to directly measure the absolute load voltage if the low voltage side of the load is chosen as the designated ground point.

\section{E. Parasitic capacitances at high frequencies}

The currents shown in Figure 4 illustrate that the transitions between current gradient polarities occur on timescale of $1 \mu \mathrm{s}$ or shorter. Therefore, any inductive components in series with the load exhibit rapid changes of their inductive voltage drops, which in turn excites any parasitic capacitances to ground. Furthermore, the capacitances between windings of inductors, such as the source inductances $\mathrm{L}_{1} \ldots \mathrm{L}_{3}$ can be excited in similar manners. These oscillations are sufficiently damped by many loads such as free-burning or blown arcs. However, loads providing little damping can be subject to significant transient overvoltages immediately following switching actions, especially if the loads also exhibit a large inductive voltage drop. In order to make FPDCS better suited for such applications, a high pass filter was designed using exclusively passive components. The filter is connected in parallel to the load (i.e. between points $\mathrm{A}$ and $\mathrm{E}$ in Figure 1), so that oscillations of frequencies above $700 \mathrm{kHz}$ bypass the load. This function is demonstrated in the two load voltages shown in Figure 5 which were measured using identical loads and current waveforms but show vastly different high frequency components.

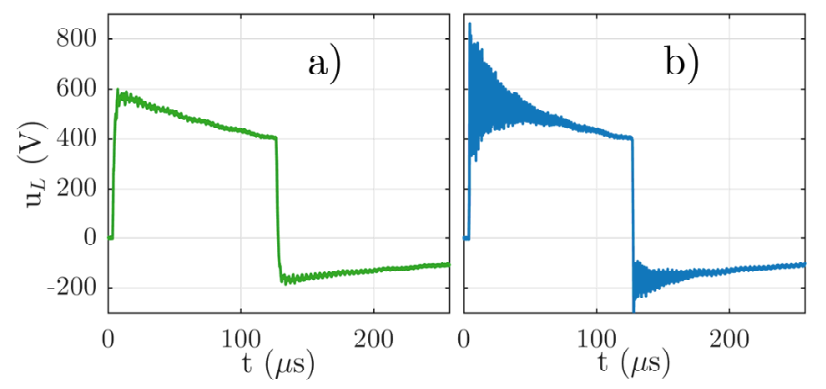

Fig. 5. Load voltages across a mostly inductive load, with (a)) and without (b)) a high pass filter using identical FPDCS and load settings.

\section{F. Controllability of the module currents}

When performing tests, FPDCS' control loop is completely decoupled from the measurement system which analyzes load current, voltage and additional parameters. However, both system share the same fundamental challenges: They require a high dynamic input range, large frequency bandwidth and minimal time lag in transmission of the measured signals. Furthermore, the significant inductive voltage drops as well as the potentially different module states at any point in time necessitate electric decoupling of most sensors. The control loop uses a custom optical fiber transmission system to relay three module shunt current measurements and three capacitor voltages to the IGBT controller, which in turn sends switching signals to the gate drivers via optical fiber. Using this control loop, delays between the current reaching a set value and IGBT turn-off is in the range of a few microseconds. Investigations into using a more sophisticated control algorithm, such as PID instead of a set current, resulted in

\footnotetext{
${ }^{3}$ a detailed study of failure modes stemming from diode reverse recovery is given by Rahimo in [11].

${ }^{4}$ In this case, the entirety of the parts between points $\mathrm{E}$ and $\mathrm{A}$ in Figure 1 is considered as load, including several meters of cabling necessary to connect the load in question.
} 
unacceptably long delays in the hundreds of microseconds between current measurement and control action.

\section{G. Voltage and current measurements}

Load voltage and current as well as additional data such as temperatures and pressures, are recorded in close proximity of the load by means of remote controlled digital storage oscilloscopes (DSO). Great care is taken when setting up measuring equipment to not introduce conducting loops in proximity to high field areas. Therefore, voltages are preferably measured using RC-dividers with high input impedance. The load current can be measured using a shunt resistance, which defines the DSO's reference level. Alternatively, a custom manufactured current sensor is available which is able to measure from pure DC to well above $1 \mathrm{MHz}$ without requiring galvanic connection to the conductor ${ }^{5}$. The latter option is particularly often used when multiple parallel current paths need to be measured inside the load.

\section{H. Safety considerations}

The basic operating principle of FPDCS relies on a high amount of energy being stored in the capacitors prior to (and often also after) each test in combination with a high operating voltage. Together with the typical dangers of pulsed current testing such as significant overpressures, high temperatures and moving parts, an automated system to protect humans as well as equipment is necessary. For this reason, a decentralized safety system which interfaces with FPDCS' components, its discharging and grounding equipment as well as with any part for human interaction (such as doors, indicator lights, emergency shutdown buttons, etc.) has been implemented. The system has been working as designed since its inception ${ }^{6}$.

\section{RECOMMENDATIONS FOR USERS}

The aforementioned eight main challenges faced when using FPDCS exemplify the complexity of such a current source as well as the multiple influencing factors concurrently imposing limits on its operation area. They also illustrate, that on similar undertakings the following aspects have to be considered as early as the planning phase:

1. Types of measurements, locations and transmission of digitized results are central to the load side of any current source. If the possibility to combine control and measurement hardware exists, it can reduce component cost.

2. Self-inductances and parasitic capacitances of current carrying parts as given by geometry and additional factors should be minimized if possible. Resonant frequencies have to be designed to be outside of typical operating areas of the DC source and its loads.

3. Energy storage, converter topology and power semiconductor choice impose the primary limitations on the applications of such a DC source. They should, therefore, be designed with the different types of loads and future expansions in mind.

4. The control loop including measurement and transmission hardware as well as software solutions present another

limitation as well as playing a central role in day-to-day operations. Great care has to be taken to account for the high dynamics of typical high current loads.

In spite of its ultimate application in a high voltage or high current laboratory, combining these four aspects into a successful DC source can only be achieved by an interdisciplinary team of specialists. The complexity of optimizing each particular aspect requires expertise spanning multiple fields such as power electronics, control, high current testing and measurement technology.

\section{CONCLUSION}

Despite the seemingly simple circuit diagram of Figure 1, FPDCS represents a complex and powerful tool for DC research which has been continuously improved upon over the past five years to a point at which different loads are being tested with confidence in the results. The experience gathered during this time has enabled the comprehensive review of the design principles and everyday challenges given in this paper. To further advance HVDC research at ETH's high voltage laboratory, a more powerful DC source is currently being designed in accordance with the four main recommendations given (cf. [14]).

\section{ACKNOWLEDGMENT}

The authors would like to express their gratitude to Dr. Michael M. Walter for planning and constructing FPDCS in its original form as well as ABB Switzerland for the expertise and financial support provided. Furthermore, the authors would like to thank Daniel Rothmund, Aditya Shekhar, Jaka Strumbelj and Stefan Franz for their contributions in improving FPDCS.

\section{REFERENCES}

[1]
R. L. Koropatnick, "HVDC Projects Listing," (selfpublished, online, March 2013), 2013. R. P. P. Smeets, A. Yanushkevich, N. A. Belda, and R. Scharrenberg, "Design of testcircuits for HVDC circuit breakers," in 20153 rd International Conference on Electric circuits for HVDC circuit breakers," in 20153 rd International Conference on El
Power Equipment - Switching Technology (ICEPE-ST), 2015, pp. 229-234. Power Equipment - Switching Technology (ICEPE-ST), 2015, pp. 229-234.
B. Bachmann, G. Mauthe, J. Porter, S. M. Ieee, J. Vithayathil, and F. Ieee, "Development of a $500 \mathrm{kV}$ AirBlast HVDC Circuit Breaker," IEEE Trans. Power Appar. Syst., no. 9, pp. 2460-2466, 1985 .

H. Nakao and Y. Nakagoshi, "DC current interruption in HVDC SF 6 gas MRTB by means of self-excited oscillation superimposition," IEEE Trans. Power Deliv., vol. 16, no. 4, pp. 687-693, 2001 .

M. M. Walter and C. M. Franck, "Flexible Pulsed DC-Source for Investigations of HVDC Circuit Breaker Arc Resistance," in XVIII International Conference on Gas Discharges and Their Applications (GD 2010), Greifswald, Germany, 2010, 2010.

J. Thomas, "Small scale testing of hvdc circuit breakers," in IEEE PES Student Prize Paper Award in Honor of T. Burke Hayes, 2014.

M. M. Walter, Switching arcs in passive resonance HVDC circuit breakers. ETH-Zürich, 2013.

M. Walter, C. Leu, and C. Franck, "Methods for direct and model independent determination of arc characteristics," IEEE Trans. Power Deliv., 2012.

L. S. J. Bort and C. M. Franck, "Effects of Nozzle and Contact Geometry on Arc Voltage in Gas Circuit-Breakers," in 2016 IEEE International Conference on High Voltage Engineering and Application, 2015, p. (in press).

Engineering and Application, 2015, p. (in press).
M. M. Walter and C. M. Franck, "Optimal Test Current Shape for Accurate Arc Characteristic Determination," IEEE Trans. Power Deliv., vol. 29, no. 4, pp. 1798-1805, Aug. 2014.

M. T. Rahimo and N. Y. A. Shammas, "Freewheeling diode reverse-recovery failure modes in IGBT applications," IEEE Trans. Ind. Appl., vol. 37, no. 2, pp. 661-670, 2001.

L. Dalessandro, N. Karrer, M. Ciappa, A. Castellazzi, and W. Fichtner, "Online and offline isolated current monitoring of parallel switched high-voltage multi-chip IGBT modules," in 2008 IEEE Power Electronics Specialists Conference, 2008, pp. 2600-2606.

J. M. Trüssel, H.-J. Weber, and C. M. Franck, "Safe and Automated Control of Experiments With a High Voltage Constuction Kit," in The 19th International Symposium on High Voltage Engineering, Pilsen, Czech Republic, August, 23 - 28, 2015, 2015, pp. 23-28.

C. Carstensen, UnACuSo: a Unipolar Arbitrary Current Source for a Hardware-in-theLoop Test Bench, PhD Thesis., no. 23189; DOI: 10.3929/ethz-a-010619905. ETH Zürich;

${ }^{5} \mathrm{Cf}$. [12] for the application of a similar sensor by the same manufacturer.

${ }^{6}$ The success of this safety system has since initiated the development and deployment of a standardized solution for all test setups at HVL (cf. [13]). 